\title{
Exploring Pre-Service Teachers' Perceptions of Their Pedagogical Preferences, Teaching Competence and Motivation
}

\section{Sadiq Abdulwahed Ahmed Ismail}

Assoc. Prof., College of Education, United Arab Emirates University, United Arab Emirates, isadiq@uaeu.ac.ae

\section{Adeeb Mohamed Jarrah}

Asst. Prof., College of Education, United Arab Emirates University, United Arab

Emirates,jarrah@uaeu.ac.ae

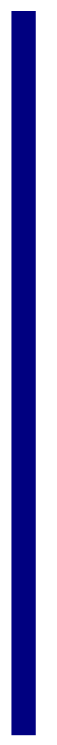

The issue of preparing qualified and motivated teachers equipped with all the essential pedagogical and content knowledge and language proficiency has recently become a top priority in many countries, including the United Arab Emirates (UAE). The main aim of the present study is to investigate the impact of teaching practice on pre-service teachers' perceptions of their pedagogical preferences, teaching competence and motivation for choosing teaching as a future career. The study employed both quantitative and qualitative methods in order to have a better understanding of the phenomenon. A five Likert scale questionnaire and a focus group interview were used to collect the necessary data. The questionnaire was distributed and collected from 30 senior prospective female teachers in both elementary and early childhood education programs in a university in the UAE, while the interviews were conducted with only 12 volunteered student teachers. The study's results revealed positive views about the two groups' pedagogical preferences, teaching competence and motivation. Many of the statistically significant results were in favour of the elementary group. Overall, a considerable number of results revealed that prospective teachers view teaching practice experience to have an impact on their pedagogical preferences, teaching competence and motivation. The study concluded with some implications and/or recommendations for future research.

Keywords: teaching, practice, competence, motivation, pedagogy

\section{INTRODUCTION}

Preparing skilful, competent and motivated teachers equipped with all the fundamental pedagogical and content knowledge and language proficiency has become a challenging priority in many countries including the UAE. The issue of training well-qualified

Citation: Ismail, S. A. A., \& Jarrah, A. M. (2019). Exploring Pre-Service Teachers' Perceptions of Their Pedagogical Preferences, Teaching Competence and Motivation. International Journal of Instruction, 12(1), 493-510. https://doi.org/10.29333/iji.2019.12132a 
teachers has even become more challenging with the introduction of English language in early stages and sometimes to be used as the medium of instruction for school subjects, such as mathematics and science. Children in the Emirate of Abu Dhabi in the UAE start learning English in kindergarten (KG) classes and English is the medium of instruction for mathematics and science subjects in elementary and middle school classes. The use of English as the medium of instruction in Abu Dhabi schools is part of a thorough educational reform plan conducted by the Abu Dhabi Education Council (ADEC). ADEC started in 2008 developing a new strategic educational plan with the participation of some stakeholders (Badri \& Al Khaili, 2014).

One of the key elements of ADEC's strategic plan was its decision to bring native English speakers to teach English, mathematics and science subjects in order to raise the level of English in its schools, including the language proficiency of local teachers who will presumably be recruited to replace the expatriate teachers. The inclusion of English as the medium of instruction in the New School Model (NSM) has in fact put more emphasis on the importance of preparing young local teachers equipped with the essential language and professional skills. The new policy requires a thorough review for the whole process of the teacher-preparation. The practice of teaching English to children is seen to be affected by the perceptions of teachers (Colwell \& Enderson, 2016; Koc \& Ilya, 2016; Meschede Fiebranz Möller \& Steffensky, 2017) Thus, it is very crucial to examine the current training status of prospective teachers and their perceptions and readiness for the newly emerging demands of teaching within the NSM system. Examining this issue will assist in developing a better understanding of prospective teachers' perceptions of teaching practice and will also facilitate the efforts to improve the process of teacher preparation. Hence, teacher education programs are expected to review their training programs in accordance with the new policy. Uibu, Salo, Ugaste, \& Rasku-Puttonen, (2017) reported that knowledge about instructionrelated beliefs is required for developing the quality of teacher education programs and responding to teacher trainees' expectations and/or needs. This study investigates the impact of teaching practice on pre-service teachers' perceptions of their pedagogical preferences, teaching competence and motivation for choosing teaching as a future career. The topic of this study is based on ADEC's new approach for introducing English as the medium of instruction for some school subjects.

\section{RESEARCH QUESTIONS}

The study sought to answers the following four research questions.

1. How do prospective teachers perceive their teaching competence while doing their teaching practice in elementary and KG schools?

2. What types of strategies do prospective teachers prefer to use in their teaching in elementary and KG schools?

3. What kinds of motivation do prospective teachers develop for becoming teachers?

4. How do prospective teachers perceive the difficulties of doing their teaching practice in elementary and KG schools? 


\section{LITERATURE REVIEW}

Teaching practice (practicum) is commonly considered as a basic component in teacher education programs (Farrell, 2003, 2007; Abdullah, Omar, Embong \& Bakar, 2015). Trainee teachers face many problems when they start doing their teaching practice in different schools with real learners. Thus, knowing their competence, motivation and pedagogical practices will presumably assist in identifying key issues which will in turn facilitate the process of reviewing and enhancing teacher preparation programs. In their study about student teachers' and school teachers' beliefs, Uibu, Salo, Ugaste \& RaskuPuttonen, (2017) reported that knowledge about instruction-related beliefs is required for enhancing quality teacher education programs. A successful teacher is viewed to be competent, motivated and possess an understanding of what constitutes good teaching practices. Persistence may also play a crucial role in shaping the future career of trainee teachers regardless of the obstacles they may encounter (Kim \& Corcoran, 2018).

Research has reported that trainee teachers during the practicum period face some challenges and/or difficulties in implementing teaching practices they were taught during their studies in teacher education programs (Uibu, Salo, Ugaste, \& Rasku-Puttonen, 2017; Gan, 2013; Mutlu, 2014; Myles, Cheng, \& Wang, 2006). In a study conducted in Hong Kong, Gan (2013) reported some results about trainee teachers' self-efficacy and pedagogical practices. Trainee students turned to abandon their earlier ideals and expectations that they learned in their program of study. They faced some difficulties when trying the innovative teaching strategies, they learned in different academic courses. Classroom managements appeared to be the most serious problem they encountered when they attempted to implement innovative teaching practices they were taught during their study. The results of this study also demonstrate that English language competence of those trainee teachers has influenced not only their teaching practices but also their professional growth. The lack of competence in pedagogical and/or teaching practices and the low English language proficiency contributed very much to the failure of the program to prepare trainee students for real classroom challenges. This evidence provides the basis for the need to investigate and understand key training issues in more depth from the point of views of all parties including the students. Results of such studies might provide program reviewers and/or developers with insights to better understand students' challenges and act accordingly.

In this regard, students should not only be left to learn independently from experience and/or practices, but they should be provided with concrete guidance and support through a systematic and well-organized mentoring procedure. In relation to the issue of mentoring, Mena, Hennissen \& Loughran, (2017) highlighted the issue of how elementary teacher trainees may develop professional knowledge of practice. They referred to autonomous learning from experience in relation to assisted learning guided by mentor teachers. They argued that it is not necessary that professional experience will fully guarantee learning about professional knowledge and practice. The results indicated that very limited learning of professional knowledge may occur as a result of experience and/or practice. They concluded their study by stating that there is a need for a well-structured and defined mentoring program to help trainee teachers acquire 
professional knowledge as relying only on experience and practice may not maximize learning.

Within the Turkish context, Gokalp (2016) examined the current teaching competencies of mathematics trainee teachers in a college of education and how much they have already acquired of those competencies. Only classroom observation instrument was utilized for collecting information about the candidates' current teaching competencies and development. The results of this study revealed that there were differences in the trainee teachers' instructional competencies and skills depending on the grade they were teaching. They were found to be more competent in lower grades than upper grades. It was also reported that in higher grade classes trainee teachers exhibited some progress in their instructional competencies and skills. The study highlighted some improvement in teacher trainees' competencies. However, Other factors such as motivation and pedagogical preferences might also have an impact on the results. Considering those variables may help in providing more concrete explanations and/or interpretations of the nature of the existing teaching competence.

In a study about trainee teachers' knowledge and competencies in establishing partnerships between schools and parents, Patte (2011) indicated that trainee teachers possess positive attitudes and motivation to promote family and school relationships though they lack the essential skills and relationship to act accordingly. Thus, the presence of positive attitudes and motivation, which are the main components of the present study, represent important factors in the success of any teacher education program. The results of Platte's study suggested that those trainee teachers are very enthusiastic and motivated to establish partnerships with family in the future when they enter the field of the teaching profession.

Motivation for becoming teachers has recently received more importance and emphasis in the literature. A number of studies based on quantitative and/or qualitative research methodology reported different results regarding trainee-teachers' motives and/or reasons for choosing the teaching profession as their future career (Maphosa, Bhebhe \& Shumba, 2014; Paulick, Retelsdorf \& Moller, 2013; Spittle, \& Spittle, 2014; Ozder \& Motorcan, 2013; Massari, 2014). Research reported that a number of intrinsic, extrinsic, and sociocultural factors may impact students' motivation to become teachers such as loving the subject matter, influence of their teachers, job security, societal incentives, holidays, etc. (Sali, 2013; Chong \& Low, 2009; Spear, Gould, \& Lee, 2000; Klassen, Al-Dhafri, Hannok \& Betts, 2011; Mtika \& Gates, 2011; Watt \& Richardson, 2008). In a study about understanding prospective teachers' perceptions for becoming English teachers, Sali (2013) reported that intrinsic, extrinsic, and sociocultural motivational factors have an influence on their choice for the teaching profession. Socio-cultural factors were found to have the greatest influence on career choice. 'Intrinsic career value' and 'loving the subject matter were also found to impact their motives to select language teaching as their main future career. Sali's results might provide some explanations for the main sources of trainee teachers' choice to become language teachers in the future. However, data of this study were only generated by using one instrument which might not lead to a thorough understanding of the motivation 
phenomenon. Triangulation of data will presumably help in examining this phenomenon from different angles.

In their study about motivation for choosing teacher education, Paulick, Retelsdorf, \& Moller (2013) examined the relationship between the motivation for choosing teaching career, teachers' instructional practices, and the accomplishments of goals. In this study, they reported results from two studies (study $1 \&$ study 2 ). In study 1 , they looked at the association between trainee teachers' motives for becoming teachers and the accomplishments of their goals, while in study 2 they investigated the additional indirect influences on trainee teachers' instructional practices. The overall results indicated that trainee teachers' motives for selecting the teaching career were influenced by actual teaching performance and mediated by the accomplishments of their goals. Hence, the results revealed that motivation for choosing the teaching career influences trainee teachers' instructional practices through the accomplishments of their goals. Intrinsic factors of their motivation for choosing the teaching career were attributed to mastery goals (Studies 1 and 2) and ability-approach goals (Study 2). Ability-approach goals were found to have relationships with adaptive instructional practices. However, when comparing these results to previous study findings, it is found that results of previous research revealed that teachers' mastery and ability approach goals are associated with teachers' well-being and job satisfaction (Retelsdorf, Butler, Streblow, Schiefele, 2010).

Reeves \& Lowenhaupt (2016) looked at prospective teachers' motivations and/or career aspirations beyond the classroom practices. They argued that teachers nowadays consider teaching not as a long-term goal, but they desire for other roles beyond the classroom. The results of their exploratory study, which was conducted within the US context, reported that teachers even before they start their teaching career have some expectations to assume certain leaderships roles. Their initial motivations for classroom teaching may be attributed to their earlier rather than later job aspirations. Thus, providing trainee teachers with leadership training and preparation before they actually join the teaching profession will help in the process of teachers' retention. The results of this study are in line with the results of previous studies such as Rinke, 2011 \& Donaldson et al., 2008.

Researchers have demonstrated growing interests in pedagogical approaches/practices, creativity and self-efficacy (Rubenstein et al., 2018; Boateng \& Sekyere, 2018; Parylo, Sungu, \& Ilgan, 2015; Dundar, 2015; Hardy, Spendlove \& Shortt, 2015; Capan, 2014;). There is evidence in the literature that trainee teachers maintain good level of selfefficacy for their pedagogical practices. Hardy, Spendlove, \& Shortt (2015) reported consistent results from two cohorts' pre-service teacher trainees. Both groups reported that they will be very competent when they go to teach in schools in the future and they will even outperform teachers in those schools. Dundar (2015) also reported positive relationships between teacher trainees' study approaches to learning and their social study teaching efficacy beliefs. It was found that there is a positive correlation between the deep learning approach in social study teaching methods course and teaching outcome expectancy beliefs. 
Sanchez, Kuchah, Rodrigues \& de Pietri, (2018) investigated how language trainee teachers during their teaching practice period may develop appropriate ideas for pedagogical practices and reflect on the impact of those pedagogies on students' progress. The findings of this study highlighted the importance of promoting conscious critical reflective practices and engagement of trainee teachers with their colleagues and students in generating and trying some innovative instructional ideas appropriate for their classes. It was reported that a number of factors have contributed to the students' success in developing ideas for certain instructional pedagogies. However, it was stated that the findings of the study should be taken with some caution since the trainee teachers haven't been exactly exposed to the same daily institutional duties and pressures that teachers usually face in their jobs. Thus, it is not clear whether those trainee teachers will continue to implement such ideas in their classes in the future when they become independent teachers. There are other factors that were not highlighted such as motivation and competency.

In a study about the relationship between pedagogical knowledge, self-efficacy and reported teaching practices, Depaepe \& Konig (2018) reported that there is no significance difference between trainee teachers' pedagogical knowledge and selfefficacy. This result is contrary to the common belief that there is always an association between general educational knowledge and self-efficacy. This is not a surprise as this result is in line with other previous studies such as Dicke et al. 2015 \& Lauermann \& Konig 2016. Another result highlighted how self-efficacy can impact the reported teaching practices. However, general pedagogical knowledge was found to have a little impact on teacher trainees' reported teaching practices.

The above brief summary and discussion of the literature reported results within the area of teacher training. Some research highlights the gap in the literature to continue investigating the issue of teacher training. Thus the main purpose of the present study is to investigate the views of prospective teachers within both the elementary and the early childhood programs in the college of education in a university in the UAE regarding their pedagogical preferences, teaching competence and motivation.

\section{METHOD}

The study employed a mixed method approach for the collection of data. In other words, both quantitative (questionnaire) and qualitative (focus group interview) methods were utilized in order to provide the participants with multiple opportunities to express their views in a better way. The mixed method design was used to serve the purpose of the study and to assist in triangulating the collection of data. In fact, this design helped in looking at the phenomenon from different angles and reaching a better understanding of the phenomenon.

\section{Participants}

The participants of this study were all senior students enrolled in both elementary and early childhood education programs in the college of education at a university in the UAE. Thirty female teacher students participated in this study by completing and returning the questionnaire (17 from the Elementary Education Program and 13 from 
the Early Childhood Program. The rationale for only focusing on thirty students is that those trainee teachers were the only available students in their final year of training. The 17 students from the Elementary Education Program received their training in different subject areas to become teachers of Arabic \& Islamic studies, English language, science $\&$ mathematics and social \& civics studies. Twelve out of the seventeen students from the Elementary Education Program were prospective English teachers. All students in the Early Childhood Program received their training to become teachers in KG schools. Students agreed to participate in the study after they were informed about the purpose and confidentiality of the study's results. English language is used as the medium of instruction for most of the courses in both programs. Most of those students have already spent at least more than three years in the College of Education. Their English language proficiency is determined by their scores in the IELTS Exam. Most of their scores fall within the score band of 5 which is the admission requirements for almost all colleges in the university at the time of collecting the data. The focus group interviews included only 12 volunteered student teachers from both the elementary and KG groups. The reason for involving only limited numbers of students in the study is due to the fact that there were only 30 senior students in both the elementary and early childhood programs at the time of conducting the present research.

\section{Questionnaire}

A questionnaire was developed by the researchers to collect the required data to answer the four research questions. The principal investigator and co-investigator drafted the items of the questionnaire and organized them in four sections in accordance with the four research questions and the purpose of the study. In other words, the study focused on four variables (pedagogical preferences, teaching competence, motivation and difficulties). The choice of those variables was based on their importance in both the literature and teacher training programs.

The validity of the instrument was established before it was used. It was given to a group of faculty members within a university to examine and provide the researchers with their comments and/or suggestions. The numbers of comments and/or suggestions given by the member of the jury were very minimal. Hence, the questionnaire was looked at and reviewed by both researchers in accordance with the comments and suggestions of the evaluators. It was found that almost all evaluators of the questionnaire agreed that there is a strong relationship between the items included in the questionnaire and the purpose and research questions of the study. Reliability was also established using the Cronbach Alpha. The value of the reliability of the questionnaire was found to be .88 which is considered as an acceptable measure for a questionnaire reliability.

\section{Focus Group Interview}

Four focus group interview questions were developed by the researchers to be used for collecting qualitative data to support the quantitative data gathered by the questionnaire. Those questions were also given to educators/researchers to look at and check if they are suitable to elicit more information to support the data obtained by the questionnaire. All these questions were reviewed and rewritten in the light of the evaluators' comments 
and/or suggestions. The participants in the focus group interview included only 12 volunteered student teachers from both the elementary and KG groups. The numbers of interviewees were selected based on their willingness to participate in the focus group interview. Additionally, the numbers of participants are considered acceptable and reasonable when looking at them in relation to the total numbers of population.

\section{Data Collection}

The questionnaire was distributed and collected from all prospective teachers during their capstone course classes which are held at the same time every week. In order to ensure full participation of all students, a research assistant helped in distributing and collecting the questionnaire from all the thirty students in both the Elementary and KG programs. Before distributing the questionnaire, the researchers and the research assistant stated clearly the purpose of the study and assured student teachers in both programs that their participation is voluntary and they may choose not to participate. The focus group interviews were conducted with two groups of four from the Elementary Education program and a group of four from the other program. Thus a total of 12 volunteered students participated in the focus group interviews conducted by the researchers and the research assistant.

\section{Data Analysis}

Both descriptive and analytical statistics (means, standard deviation \& T-Test) were used to analyse the data obtained from the questionnaire. The T-test was obtained to determine if there are any significant differences between the views of the student teachers in both the elementary and the early childhood programs. The use of the t-test analysis was determined by the mean scores obtained for each group and the overall mean scores of both groups. The qualitative data were organized and categorized into themes and/or recurrent patterns. Following a qualitative analysis technique suggested by Patton (2002), the researcher looked at "the details and specifics" of the data collected via the focus group interviews. The main purpose for using the qualitative techniques suggested by Patten was to make sure that the obtained recurrent patterns/themes are relevant to the purpose of the study and they may assist in discussing and supporting the quantitative results of the questionnaire. The use of Patten's method may help in identifying the unanticipated elements obtained by using some open-ended interview questions.

The data was organized, categorized into themes and represented in tables and/or charts to make it more visible. Initially, the data was categorized and put into themes and later the frequency of each theme and/or item was counted and recorded in order to trace recurrent patterns. The qualitative results obtained from the focus group interviews only used to support the discussion of the key quantitative results obtained from the questionnaire. In other words, the discussion of results was mainly focused on the results obtained from the questionnaire and the qualitative results were looked at to find out if there is any consistency or discrepancy between the two sets of results. In brief, the qualitative results were only used to support the discussion of the quantitative results obtained from the questionnaire. 


\section{FINDINGS AND DISCUSSION}

To answer question 1 (How do prospective teachers perceive their teaching competence while doing their teaching practice in elementary and KG schools?), the overall mean score for all results was calculated to determine the average value. The overall mean score was found to be 4.39 which is considered to be a high result. When considering the overall difference, the result indicates no significant difference between the two groups (elementary and KG prospective teachers) (see table 1). Item 2 (engaging students in learning) has the highest overall mean score ( $\mathrm{M}=4.60)$, while the item with the overall lowest mean score $(\mathrm{M}=4.13)$ is item 9 (use diverse questioning techniques). The mean scores of the first group (Elementary Prospective teachers) range between 4.88 (engage students in learning; establish good rapport with students) and 4.29 (Use diverse questioning techniques)' while the second group's (KG prospective teachers) mean scores range between 4.46 (assess student learning) and 3.77 (plan for mix-ability students; use different teaching techniques).

Table 1 demonstrates that a considerable statistically significant differences exist between the two groups in favour of the elementary group. These results may be interpreted in relation to trainee teachers' self-efficacy. Elementary school trainee teachers may have been exposed to multiple experience and strategies to teach different subjects while the focus in the early childhood program is mainly on instructional strategies relevant to literacy development. These results are supported by findings reported by previous studies such as the results reported by Depaepe \& Konig, 2018; Hardy, Spendlove \& Shortt, 2015; Dundar, 2015. One of the results reported by Depaepe \& Konig (2018) highlighted how self-efficacy may impact the reported teaching practices. The results can also be interpreted in relation to the nature of teaching in KG and elementary classes, especially in upper-elementary classes. They might also be attributed to elementary children's ages which enable prospective teachers to implement instructional practices such as "engaging students in learning, planning for mix-ability students, co-teaching with the class teacher and designing additional activities and/or exercises" more than KG trainee teachers. These results are in line with the findings reported by Gokalp (2016) who reported that trainee teachers were found to be more competent in higher grades than lower grades. The results of the focus group interview, for example, provide clear support for the result of item 11 (using different teaching techniques). A number of elementary trainee students highlighted that they use different teaching techniques in their classes including those used in KG classes such as games, moving pictures, circle-time, songs, etc. Generally, the interviews' results revealed that both groups of prospective teachers implement almost the same teaching practices but at different degrees and levels.

Table 1

Prospective Teachers' Perceptions of their Teaching Competence While Doing their Teaching Practice in Elementary and KG Schools

\begin{tabular}{|c|c|c|c|c|c|c|}
\hline \multirow[t]{2}{*}{ During my teaching practice I was able to: } & \multirow[t]{2}{*}{$\begin{array}{l}\text { Overall } \\
\text { Mean }\end{array}$} & SD & \multicolumn{2}{|l|}{ Means } & $\begin{array}{l}\text { T- } \\
\text { Test }\end{array}$ & $\begin{array}{l}\text { Sig } \\
\text { (2tailed) }\end{array}$ \\
\hline & & & Elm & KG & & \\
\hline Prepare concrete lesson plans & 4.33 & .66 & 4.53 & 4.08 & 1.95 & .062 \\
\hline
\end{tabular}




$\begin{array}{llllllll}2 & \text { Engage students in learning } & 4.60 & .62 & 4.88 & 4.23 & 3.29 & .003 \\ 3 & \text { Plan for mix-ability students } & 4.23 & .73 & 4.59 & 3.77 & 3.64 & .001 \\ 4 & \text { Co-teach with the class teacher } & 4.30 & .88 & 4.65 & 3.85 & 2.74 & .010 \\ 5 & \text { Design additional activities and/or exercises } & 4.43 & .78 & 4.77 & 4.00 & 3.04 & .005 \\ 6 & \text { Create an attractive learning environment } & 4.43 & .78 & 4.65 & 4.16 & 1.80 & .083 \\ 7 & \text { Manage students' behaviour } & 4.24 & .83 & 4.53 & 3.83 & 2.41 & .023 \\ 8 & \text { Manage the use of the white board } & 4.40 & .77 & 4.47 & 4.31 & .57 & .58 \\ 9 & \text { Use diverse questioning techniques } & 4.13 & .78 & 4.29 & 3.92 & 1.31 & .200 \\ 10 & \text { Use diverse resources to assist learning and } & 4.40 & .68 & 4.53 & 4.23 & 1.21 & .24 \\ & \text { teaching } & & & & & & \\ 11 & \text { Use different teaching techniques } & 4.30 & .75 & 4.71 & 3.77 & 4.29 & .000 \\ 12 & \text { Interact with students very well } & 4.50 & .73 & 4.71 & 4.23 & 1.83 & .077 \\ 13 & \text { Establish good rapport (relationship) with students } & 4.57 & .73 & 4.88 & 4.15 & 3.09 & .004 \\ 14 & \text { Give feedback to students } & 4.53 & .57 & 4.65 & 4.39 & 1.26 & .218 \\ 15 & \text { Assess students' learning } & 4.50 & .73 & 4.53 & 4.46 & .248 & .806 \\ & \text { Overall } & 4.39 & .74 & 4.63 & 4.09 & 2.18 & .154\end{array}$

Table 2 demonstrates the results of research question 2 (What types of strategies do prospective teachers prefer to use in their teaching in elementary and KG schools). The overall mean sores for all items ranged between 4.50 and 3.93. The elementary group's mean scores range between 4.71 and 4.06 while the KG group's mean scores range between 4.62 and 3.62. When comparing between the results of the two groups, it is found that five results demonstrate statistically significant differences in favour of the elementary group (items $17,22,23,25,26$ ). These differences may be related to the pedagogical courses that both groups were offered in their programs of studies. The elementary prospective teachers are exposed to more pedagogical courses than KG prospective teachers. Another reason could be attributed to the kinds of activities offered in elementary classes such as 'presentation', 'demonstration', 'individual assignments', etc. In elementary classes teachers, for example, may use 'questioning' as a kind of technique to facilitate students' learning, while KG teachers may use other appropriate scaffolding techniques more than the questioning procedure. It might also be attributed to the kinds of mentoring and guidance that both groups were receiving. There is some support in the literature for this result such as the results reported by Mena, Hennissen \& Loughran (2017) who discussed how elementary school trainee teachers may develop professional knowledge and practices. They discussed that independent learning might not fully assist in learning and/or developing instructional practices unless it is supported by a systematic and well-organized mentoring procedure.

All in all, the statistically significant differences might be attributed to the methods of teaching used in elementary and KG schools, ages of children, teacher-preparation programs, individual differences, self-efficacy, motivation, etc. (Uibu, Salo, Ugaste \& Rasku-Puttonen, 2017; Mutlu 2014; Gan 2013). The two groups' answers for the interview questions provide also clear support for the results of this research question. Participants of the two groups highlighted some different activities/strategies they have been using in their classes such as questioning techniques, demonstrations \& presentations (elementary group) and games, songs \& moving pictures (KG group). 
Table 2

Types of Strategies Prospective Teachers Prefer to Use in their Teaching in Elementary and KG Schools

\begin{tabular}{|c|c|c|c|c|c|c|c|}
\hline \multirow{3}{*}{\multicolumn{2}{|c|}{$\begin{array}{l}\text { During my teaching practice I preferred } \\
\text { to use the following strategies in my } \\
\text { teaching: }\end{array}$}} & \multirow{3}{*}{$\begin{array}{l}\text { Overall } \\
\text { Mean }\end{array}$} & SD & \multirow{2}{*}{\multicolumn{2}{|c|}{ Means }} & \multirow{3}{*}{$\begin{array}{l}\text { T- } \\
\text { Test }\end{array}$} & \multirow{3}{*}{$\begin{array}{l}\text { Sig } \\
\text { (2tailed) }\end{array}$} \\
\hline & & & & & & & \\
\hline & & & & Elm & KG & & \\
\hline 16 & Acting & 4.37 & .93 & 4.35 & 4.39 & .091 & .928 \\
\hline 17 & Presentations & 4.47 & 63 & 4.71 & 4.15 & 2.61 & .014 \\
\hline 18 & Interactive activities & 4.48 & .63 & 4.59 & 4.33 & 1.07 & .294 \\
\hline 19 & Out of class activities & 3.93 & 1.20 & 4.18 & 3.62 & 1.28 & .211 \\
\hline 20 & Whole class discussion & 4.03 & .85 & 4.06 & 4.00 & .185 & .855 \\
\hline 21 & $\begin{array}{l}\text { Exploration and/or discovery } \\
\text { activities }\end{array}$ & 4.07 & .74 & 4.29 & 3.77 & 2.02 & .052 \\
\hline 22 & $\begin{array}{l}\text { Provide demonstrations for } \\
\text { students }\end{array}$ & 4.32 & .78 & 4.69 & 3.83 & 3.42 & .002 \\
\hline 23 & $\begin{array}{l}\text { Questioning students to check } \\
\text { understanding. }\end{array}$ & 4.37 & .62 & 4.59 & 4.08 & 2.44 & .021 \\
\hline 24 & Group assignments & 4.17 & 1.15 & 4.41. & 3.85 & 1.36 & .185 \\
\hline 25 & Individual assignments & 4.41 & .82 & 4.71 & 4.00 & 2.47 & .020 \\
\hline 26 & Questioning techniques & 4.43 & .78 & 4.71 & 4.08 & 2.38 & .025 \\
\hline \multirow[t]{2}{*}{27} & Problem solving activities & 4.50 & .68 & 4.41 & 4.62 & .805 & .428 \\
\hline & Overall & 4.30 & .82 & 4.48 & 4.06 & 1.68 & .253 \\
\hline
\end{tabular}

Table 3 displays all the results of research question 3 (What kinds of motivation do prospective teachers develop for becoming teachers?). The overall mean score for the two groups is 4.33 . The elementary group's mean scores range between 4.77 (working with children) and 3.12 ('Considering the number of holidays'), while the mean scores of the KG group range between 4.50 (observing other teachers) and 4.08 ('working with children'; 'considering the number of holidays'; 'studying in my university program'). When considering the overall differences between the two groups, it is found that there is no statistically significant difference, but there are two statistically significant differences between the results of individual items; one is in favour of the elementary group (item 29: 'working with children') and the other is in favour of the KG group (item 33: 'considering the number of holidays'). Generally, those differences between the two groups may be attributed to the amount and nature of involving trainee teachers in teaching children in elementary and KG schools. In elementary schools they are assigned to teach specific subjects such as mathematics, science, Arabic language, English language, Islamic education, social studies and civics, while the KG group may teach very limited subjects in Arabic. Thus, it is obvious that the level of engagements in teaching practice may impact motivational factors.

A number of previous study reported similar results that emphasized the role of motivation in shaping the future career of trainee teachers (Sali, 2013; Massari, 2014; Mtika \& Gates, 2011; Chong \& Low, 2009; Ozder \&Motorcan, 2013; Spittle \& Spittle, 2014). In Sali's study, for example, motivational factors were found to have an impact on trainee teachers' choices for their teaching career. The sociocultural factors were reported to have the greatest influence on their decision for their career choice. Other evidence in the literature was also found in the work of Paulic, Retelsdorf \& Moller, 2013; Klassen, Al-Dhafri, Hannok \& Betts, 2011; Maphosa, Bhebhe \& Shumba, 2014; 
Sali, 2013; Watt \& Richardson, 2008. The overall results reported by Paulic, Retelsdorf \& Moller, (2013) revealed that trainee teachers' selection of the teaching career is affected by their instructional practices and mediated by the accomplishments of their goals. Reeves \& Lowenhaupt (2016) reported that today trainee teachers' motivation and aspirations go beyond the classroom. Results within the same line were also reported by Rinke, 2011; Donadlson et al., 2008. During the focus group interviews, participants from both elementary and $\mathrm{KG}$ groups indicated that they developed their love for teaching (motivation) from working with children.

Table 3

Kinds of Motivation Prospective Teachers Develop for Becoming Teachers

\begin{tabular}{|c|c|c|c|c|c|c|c|}
\hline \multirow{2}{*}{\multicolumn{2}{|c|}{$\begin{array}{l}\text { I developed my attitude towards the } \\
\text { teaching profession as a result of: }\end{array}$}} & \multirow[t]{2}{*}{$\begin{array}{l}\text { Overall } \\
\text { Mean }\end{array}$} & \multirow[t]{2}{*}{ SD } & \multicolumn{2}{|c|}{ Means } & \multirow[t]{2}{*}{$\begin{array}{l}\text { T- } \\
\text { Test } \\
\end{array}$} & \multirow[t]{2}{*}{$\begin{array}{l}\text { Sig } \\
\text { (2tailed) }\end{array}$} \\
\hline & & & & Elm & KG & & \\
\hline 28 & $\begin{array}{l}\text { Getting encouragement and/or } \\
\text { feedback from others. }\end{array}$ & 4.57 & .57 & 4.71 & 4.39 & 1.57 & .127 \\
\hline 29 & Working with children & 4.47 & .63 & 4.77 & 4.08 & 3.50 & .002 \\
\hline 30 & Wanting to be a teacher & 4.40 & .72 & 4.53 & 4.23 & 1.13 & .270 \\
\hline 31 & Observing other teachers & 4.62 & .62 & 4.71 & 4.50 & .874 & .390 \\
\hline 32 & Working in a female school & 4.47 & .82 & 4.53 & 4.39 & .473 & .640 \\
\hline 33 & $\begin{array}{l}\text { Considering the number of } \\
\text { holidays }\end{array}$ & 3.53 & 1.04 & 3.12 & 4.08 & 2.77 & .010 \\
\hline 34 & Listening to my family advice & 4.23 & .97 & 4.12 & 4.39 & .740 & 465 \\
\hline 35 & Loving the subject matter & 4.43 & .63 & 4.53 & 4.31 & .960 & .345 \\
\hline 36 & $\begin{array}{l}\text { Studying in my university } \\
\text { program }\end{array}$ & 4.27 & .58 & 4.41 & 4.08 & 1.60 & .121 \\
\hline 37 & $\begin{array}{l}\text { Attending professional } \\
\text { development activities }\end{array}$ & 4.33 & .71 & 4.41 & 4.23 & .684 & 499 \\
\hline & Overall & 4.33 & .73 & 4.38 & 4.27 & 1.43 & .287 \\
\hline
\end{tabular}

The results of research question 4 (How do prospective teachers perceive the difficulties of doing their teaching practice in elementary and KG schools?) are presented in table 4. All the results of this research question are found to be low when they are considered either collectively or individually. The overall mean score for all items is 2.95. The mean scores of the elementary group range from 3.24 (managing time) and 2.29 (teaching different lessons), while the mean scores of the $\mathrm{KG}$ group range between 3.62 (teaching different lessons; Doing other activities such as clerical work) and 3.08 (managing a disruptive class; assessing learning outcomes). The overall results of the two groups reveal no statistically significant differences between the two groups. However, four individual results demonstrate statistically significant differences between the two groups' views about the difficulties they face when doing their teaching practice (item 42: teaching different lessons; item: 44 doing other activities such as clerical work; item 47: Experiencing unfriendly relationship with the school; item 50: having language problems).

Unlike the results of the other research questions, all the statistically significant differences about the difficulties they faced are in favour of the KG group. Those results may be interpreted in relation to the nature and system of instruction in both $\mathrm{KG}$ 
and elementary schools. For example, the language problems that GK group face might be attributed to the fact that English language is the medium of instruction in their university program, but they have to use Arabic language in teaching children during their practicum sessions. In their comments during the focus group interview sessions, participants from both groups focused more on the procedures they use to deal with problems rather than just stating those problems. They also reported having problems deciding on the right methods and/or instructional strategies for teaching different lessons. Similar results were reported by Colwell and Enderson (2016) about understanding mathematical literacy instruction. They reported that prospective teachers indicated that the difficulties they found in understanding mathematical literacy instruction during some course work hindered them from implementing certain kinds of instruction. Gan (2013) found that trainee teachers tend at the beginning to use the innovative ideas they have learned in their program of study, but later they turned to abandon them due to the difficulties they face. Classroom management was one of the serious problems they faced when they tried to implement innovative strategies they were trained to use. Other supports and evidence for those results were also found in the literature (Uibu, Salo, Ugaste, \& Rasku-Puttonen, 2017; Gan, 2013; Mutlu, 2014; Myles, Cheng, \& Wang, 2006).

Table 4

Prospective Teachers Perceived Difficulties of Doing their Teaching Practice in Elementary and KG Schools

\begin{tabular}{|c|c|c|c|c|c|c|c|}
\hline \multirow{2}{*}{\multicolumn{2}{|c|}{$\begin{array}{l}\text { I faced the following difficulties when doing } \\
\text { my teaching practice: }\end{array}$}} & \multirow{3}{*}{$\begin{array}{l}\begin{array}{l}\text { Overall } \\
\text { Mean }\end{array} \\
3.17\end{array}$} & \multirow{3}{*}{$\begin{array}{l}\text { SD } \\
1.42\end{array}$} & \multirow{2}{*}{$\begin{array}{l}\text { Means } \\
\text { Elm }\end{array}$} & \multirow{3}{*}{$\begin{array}{l}\text { KG } \\
3.54 \\
\end{array}$} & \multirow{2}{*}{$\begin{array}{l}\begin{array}{l}\text { T- } \\
\text { Test }\end{array} \\
1.27\end{array}$} & \multirow{2}{*}{$\begin{array}{l}\begin{array}{l}\text { Sig } \\
\text { (2tailed) }\end{array} \\
.214\end{array}$} \\
\hline & & & & & & & \\
\hline 38 & $\begin{array}{l}\text { Designing and/or selecting materials } \\
\text { for each lesson }\end{array}$ & & & 2.88 & & & \\
\hline 39 & $\begin{array}{l}\text { Receiving inadequate guidance and/or } \\
\text { instruction }\end{array}$ & 2.91 & 1.18 & 2.77 & 3.25 & 1.09 & .283 \\
\hline 40 & Managing a disruptive class & 3.04 & 1.15 & 3.00 & 3.08 & .176 & .861 \\
\hline 41 & $\begin{array}{l}\text { Facing difficulties to determine the } \\
\text { right learning outcomes }\end{array}$ & 2.93 & 1.23 & 2.77 & 3.15 & .855 & .400 \\
\hline 42 & Teaching different lessons & 2.87 & 1.41 & 2.29 & 3.62 & 2.84 & .008 \\
\hline 43 & $\begin{array}{l}\text { Covering classes for absent or busy } \\
\text { teachers }\end{array}$ & 2.93 & 1.32 & 2.53 & 3.46 & 2.03 & .052 \\
\hline 44 & $\begin{array}{l}\text { Doing other activities such as clerical } \\
\text { work }\end{array}$ & 2.90 & 1.24 & 2.31 & 3.62 & 3.28 & .003 \\
\hline 45 & Organizing classroom activities & 2.90 & 1.42 & 2.65 & 3.23 & 1.11 & .273 \\
\hline 46 & Managing time & 3.20 & 1.32 & 3.24 & 3.15 & .164 & .871 \\
\hline 47 & $\begin{array}{l}\text { Experiencing unfriendly relationship } \\
\text { with the school }\end{array}$ & 2.87 & 1.43 & 2.41 & 3.46 & 2.10 & .044 \\
\hline 48 & Assessing learning outcomes & 2.80 & 1.27 & 2.59 & 3.08 & 1.04 & .305 \\
\hline 49 & Teaching diverse students & 2.90 & 1.37 & 2.50 & 3.39 & 1.79 & .084 \\
\hline 50 & Having language problems & 2.93 & 1.26 & 2.53 & 3.46 & 2.13 & .042 \\
\hline 51 & $\begin{array}{l}\text { Implementing what I learned at the } \\
\text { university }\end{array}$ & 3.00 & 1.39 & 2.65 & 3.50 & 1.68 & .104 \\
\hline & Overall & 2.95 & 1.32 & 2.65 & 3.36 & 1.54 & .253 \\
\hline
\end{tabular}




\section{CONCLUSION}

In summary, the present study attempted to investigate the four variables (pedagogical preferences, teaching competence, motivation and difficulties) that may impact the success of any teacher education programs either positively or negatively. The study was conducted to examine the impact of teaching practice experience on both elementary and KG prospective teachers' perceptions of their pedagogical preferences, teaching competence and motivation. It also looked at their views of the difficulties they faced when they do their practicum. Overall, a considerable number of results revealed that prospective teachers view teaching practice experience to have an impact on their pedagogical preferences, teaching competence and motivation. Generally, it was found that prospective teachers were using different instructional strategies at different degrees and levels. The results also indicate that the two groups faced different levels of difficulties when they do their practicum. Results of the four questions revealed a number of statistically significant differences mostly in favour of the elementary group.

\section{IMPLICATIONS}

The results of this study may have implications for different groups at all levels ascending from classroom teachers to decision makers. Teacher education program coordinators may benefit from those results in restructuring their programs in a better way to meet student teachers' needs and/or expectations. Mentor teachers and supervisors of student teachers may use the results to review their mentoring and supervision procedures to facilitate difficulties and encourage candidates to be more involved in their training programs. Student teachers may also benefit from those results in different ways such as becoming more aware about the efforts they have continuously been making and the challenges they may face at the beginning of their professional career. Overall, those sets of implications may contribute directly and indirectly towards the enhancement of teacher education programs in general and elementary teacher training programs and early childhood education programs in particular. Although the results of this study have a considerable contributions and help in understanding trainee teachers' views of their competence, pedagogical knowledge and problems, there is still a need to conduct more research to examine their actual practices. Large scale studies may also come with more concrete results. 


\section{REFERENCES}

Abdullah, A. H., Omar, M. C., Embong, R., \& Bakar, N. S. A. (2015). The Perception Towards Practicum Experience among Islamic Education Preservice Teachers in University Sultan Zainalabidin (UnisZA), Terengganu, Malaysia. Middle-East Journal of Scientific Research, 23(4), 695-705.

Badri, M., \& Al Khaili, M. (2014). Migration of P-12 Education from its Current State to One of High Quality: The Aspirations of Abu Dhabi. Policy Futures in Education, 12(2), 200-220.

Boateng, P., \& Sekyere, F. O. (2018). Exploring in-Service Teachers' Self-Efficacy in the Kindergarten Classrooms in Ghana. International Journal of Instruction, 11(1), 239254.

Capan, S. (2014). Pre-Service English as a Foreign Language Teachers' Belief Development about Grammar Instruction. Australian Journal of Teacher Education, 39(12), 131-152.

Chong, S. \& Low, E. L. (2009). Why I want to teach and how I feel about teachingformation of teacher identity from pre-service to the beginning teacher phase. Educational Research Policy and Practice, 8, 59-72.

Colwell, J., \& Enderson, M. C. (2016). "When I hear literacy": Using pre-service teachers' perceptions of mathematical literacy to inform program changes in teacher education. Teaching and Teacher Education, 53, 63-74.

Depaepe, F., \& Konig, J. (2018). General pedagogical knowledge, self-efficacy and instructional practice: Disentangling their relationship in pre-service teacher education. Teaching and Teacher Education, 69, 177-190.

Dicke, T., Parker, P. D., Holzberger, D., Kunina-Habenicht, O., Kunter, M., \& Leutner, D. (2015). Beginning teachers' self-efficacy and emotional exhaustion: Latent changes, reciprocity, and the influence of professional knowledge. Contemporary Educational Psychology, 41, 62-72.

Donaldson, M. L., Johnson, S. M., Kirkpatrick, C. L., Marinell, W. H., Steele, J. L., \& Szczesiul, S. A. (2008). Angling for access, bartering for change: How second stage teachers experience differentiated roles in schools. The Teachers College Record, $110(5), 1088-1114$.

Dundar, Ş. (2015). Are Prospective Elementary School Teachers' Social Studies Teaching Efficacy Beliefs Related to Their Learning Approaches in a Social Studies Teaching Methods Course?. Australian Journal of Teacher Education, 40(7). 70-85.

Farrell, T. (2007). Failing the practicum: Narrowing the gap between expectations and reality with reflective practice. TESOL Quarterly, 41(1), 193-201.

Farrell, T. (2003) Learning to teach English language during the first year: personal influences and challenges. Teaching and Teacher Education 19(1) 95-111. 
Gan, Z. (2013). Learning to teach English language in the practicum: What challenges do non-native ESL student teachers face?. Australian Journal of Teacher Education, 38(3), 92-108.

Gokalp, M. (2016). Investigating classroom teaching competencies of pre service elementary mathematics teachers. Eurasia Journal of Mathematics, Science \& Technology Education, 12(3), 503-512.

Hardy, G., Spendlove, D., \& Shortt, D. (2015). Changing Expectations, Same Perspective: Pre-service Teachers' Judgments of Professional Efficacy. Australian Journal of Teacher Education, 40(2), 146-169.

Kim, E., \& Corcoran, R. P. (2018). Factors that influence pre-service teachers' persistence. Teaching and Teacher Education, 70, 204-214.

Klassen, R. M., Al-Dhafri, S., Hannok, W. \& Betts, S. M. (2011). Investigating preservice teacher motivation across cultures using the Teachers' Ten Statements Test. Teaching and Teacher Education, 27, 579-588.

Koc, B., \& Ilya, A. (2016). Exploring Pre-service Language Teachers $\square$ Perceptions and Actual Practices of Giving Feedback in Micro-teaching. Procedia-Social and Behavioural Sciences, 232, 421-429.

Lauermann, F., \& Konig, J. (2016). Teachers' professional competence and wellbeing:

Understanding the links between general pedagogical knowledge, self-efficacy, and burnout. Learning and Instruction, 45, 9-19.

Maphosa, C., Bhebhe, S., \& Shumba, J. (2014). 'What Motivated Them to Become teachers?'An Examination of Trainee Teachers' Motives of Training as Teachers. Mediterranean Journal of Social Sciences, 5(7), 482-490.

Massari, G. A. (2014). Motivation for teaching career of students from early childhood education and primary school pedagogy. Acta Didactica Napocensia,7(4),1-6.

Mena, J., Hennissen, P., \& Loughran, J. (2017). Developing pre-service teachers' professional knowledge of teaching: The influence of mentoring. Teaching and Teacher Education, 66, 47-59.

Meschede, N., Fiebranz, A., Möller, K., \& Steffensky, M. (2017). Teachers' professional vision, pedagogical content knowledge and beliefs: On its relation and differences between pre-service and in-service teachers. Teaching and teacher education, 66, 158-170.

Mtika, P., \& Gates, P. (2011). What do secondary trainee teachers say about teaching as a profession of their "choice" in Malawi?. Teaching and Teacher Education, 27(2), 424-433.

Mutlu, G. (2014). Challenges in Practicum: Pre-Service and Cooperating Teachers' Voices. Journal of Education and Practice, 5(36), 1-7, 
Myles, J., Cheng, L., \& Wang, H. (2006). Teaching in elementary school: Perceptions of foreign-trained teacher candidates on their teaching practicum. Teaching and Teacher education, 22(2), 233-245.

Ozder, H., \& Motorcan, A. (2013). An analysis of teacher candidates' academic motivation levels with respect to several variables. British Journal of Arts and Social Sciences, 15(1), 42-53.

Parylo, O., Süngü, H., \& Ilgan, A. (2015). Connecting Attitudes Toward Teaching and Pedagogical Formation Courses: A Study of Turkish Pre-Service Teachers. Australian Journal of Teacher Education, 40(5), 85-102.

Patte, M. M. (2011). Examining preservice teacher knowledge and competencies in establishing family-school partnerships. School Community Journal, 21 (2), 143.

Patton, M. Q. (2002). Qualitative Research and Evaluation Methods (3 ${ }^{\text {rd }}$ ed.). Thousand Oaks, CA: Sage Publications, Inc.

Paulick, I., Retelsdorf, J., \& Moller, J. (2013). Motivation for choosing teacher education: Associations with teachers' achievement goals and instructional practices. International Journal of Educational Research, 61, 60-70.

Reeves, T. D., \& Lowenhaupt, R. J. (2016). Teachers as leaders: Pre-service teachers' aspirations and motivations. Teaching and Teacher Education, 57, 176-187.

Retelsdorf, J., Butler, R., Streblow, L., \& Schiefele, U. (2010). Teachers' goal orientations for teaching: Associations with instructional practices, interest in teaching, and burnout. Learning and Instruction, 20, 30-46.

Rinke, C. R. (2011). Career trajectories of urban teachers: A continuum of perspectives, participation, and plans shaping retention in the educational system. Urban Education, 46(4), 639-6620.

Rubenstein, L. D., Ridgley, L. M., Callan, G. L., Karami, S., \& Ehlinger, J. (2018). How teachers perceive factors that influence creativity development: Applying a Social Cognitive Theory perspective. Teaching and Teacher Education, 70, 100-110.

Sal1, P. (2013). Understanding Motivations to Become Teachers of English: ELT Trainees' Perceptions. Procedia-Social and Behavioral Sciences, 93, 1418-1422.

Sanchez, H. S., Kuchah, K., Rodrigues, L., \& de Pietri, E. (2018). Pre-service language teachers' development of appropriate pedagogies: A transition from insightful critiques to educational insights. Teaching and Teacher Education, 70, 236-245.

Spear, M., Gould, K., \& Lee, B. (2000). Who Would be a Teacher?: A Review of Factors Motivating and Demotivating Prospective and Practising Teachers. Slough: NFER.

Spittle, S., \& Spittle, M. (2014). The Reasons and Motivation for Pre-Service Teachers Choosing to Specialise in Primary Physical Education Teacher Education. Australian Journal of Teacher Education, 39(5), 1-25. 
Uibu, K., Salo, A., Ugaste, A., \& Rasku-Puttonen, H. (2017). Beliefs about teaching held by student teachers and school-based teacher educators. Teaching and Teacher Education, 63, 396-404.

Watt, H. M. G. \& Richardson, P. W. (2008). Motivation for teaching. Learning and Instruction, 18 (5), 405-407. 